\title{
Gastroesophageal reflux disease: a practical approach
}

\author{
Gerson DOMINGUES ${ }^{1}$ and Joaquim Prado P de MORAES-FILHO
}

Received: 20 May 2021 Accepted: 26 June 2021

ABSTRACT - Gastroesophageal reflux disease (GERD) presents typical manifestations such as heartburn and/or regurgitation as well as atypical manifestations such as throat symptoms, laryngitis, hoarseness, chronic cough, asthma, and sleep alterations. There are two phenotypes of the disease: erosive GERD, when erosions are identified by upper digestive endoscopy, and non-erosive GERD, when the esophageal mucosa presents a normal endoscopic aspect. Relevant clinical findings are usually absent in the physical examination, but it should be highlighted that obesity is an important aggravating factor of reflux. The treatment is established based on clinical findings and, according to the clinical situation, on complementary exams such as upper digestive endoscopy. In dubious cases where a precise diagnosis is required, the indicated test is esophageal pHmetry or impedance-pHmetry. Clinical treatment is divided into behavioral/dietary measures and pharmacological measures. Most patients benefit from clinical treatment, but surgical treatment may be indicated in the presence of a larger hiatal hernia and complications of the disease.

Keywords - Gastroesophageal reflux disease; diagnosis; treatment.

\section{INTRODUCTION}

Gastroesophageal reflux disease (GERD) is a chronic condition that develops when reflux of the gastric contents causes troublesome symptoms and/or complications ${ }^{(1)}$. It is one of the most common diagnoses among outpatients of the gastroenterology clinic $^{(1)}$.

A population-based study covering approximately 14,000 people in 22 cities in different regions identified a prevalence of approximately $12 \%$ to $20 \%$ in the urban Brazilian population ${ }^{(2)}$.

A very important aspect of the disease is the reduction in the quality of life of the affected individuals. For example, the quality of sleep of the affected individuals might be compromised since nocturnal reflux is relatively frequent, causing awakenings, REM sleep interruptions, and the shortening of the individual's sleep time $^{(3)}$. In addition to health as a whole, the reduction in quality of life has negative consequences on social activities and labor productivity, with a resulting financial impact (absenteeism, cost of medication, medical consultations, loss of working hours, etc).

Traditionally, when GERD is suspected, an acid-suppressive medication is started, particularly proton pump inhibitors (PPIs). However, up to $40 \%$ of these patients treated with PPIs may show incomplete or no response to therapy ${ }^{(4-6)}$.

\section{METHODS}

In order to achieve a comprehensive narrative review, the relevant literature was assessed in Pubmed, Medline, and other sources using the following search terms: heartburn, pyrosis, gastroesophageal reflux, GERD, refluxate, endoscopy of gastroesophageal reflux disease, esophagitis, and esophageal motility.

\section{Etiopathogenesis and pathophysiology}

The process by which gastroesophageal reflux causes GERD consists of a sequence of events that involve the esophagogastric junction (EGJ) and esophageal body, as well as mechanisms of visceral sensitivity regulation mediated by the central and peripheral nervous system. The imbalance between protective and aggressive factors is responsible for the development of GERD.

The main protective factors are the lower esophageal sphincter (LES), saliva, peristalsis, and the angle of esophageal passage through the hiatus (angle of Hiss). The aggressive factors are represented by the transient lower esophageal sphincter relaxations, hypotension of the LES, refluxed gastric acid $\mathrm{pH}$, increased distensibility of the LES, prolonged esophageal clearance, reduced gastric emptying speed, and hiatus hernia ${ }^{(7)}$.

\section{Anti-reflux barrier}

\section{Esophagogastric junction and angle of Hiss}

The EGJ involves the superposition of the lower esophageal sphincter and the diaphragmatic crura (DC) and represents the anti-reflux barrier ${ }^{(7,8)}$, the main defensive factor. The LES maintains a zone of high pressure due to the tone of the intrinsic muscles and the excitatory stimulation of cholinergic neurons ${ }^{(9)}$. The diaphragmatic crura provides extrinsic compression to the LES, contributing to the resting pressure, with approximately 5 to $10 \mathrm{mmHg}^{(10)}$

The oblique entry of the esophagus into the stomach creates an acute angle with the great gastric curvature, called Hiss angle, which creates a valve effect that contributes to the competence of the $\mathrm{EGJ}^{(8)}$.

Declared conflict of interest: Domingues G: lecture for AstraZeneca, Takeda Advidory Board. Moraes-Filho JP: publication for Reckitt-Benkiser, Takeda Advirory Board.

Disclosure of funding: no funding received

Faculdade de Ciências Médicas, Universidade do Estado do Rio de Janeiro, Rio de Janeiro, RJ, Brasil. ${ }^{2}$ Faculdade de Medicina da Universidade de São Paulo, São Paulo, SP, Brasil.

Corresponding author: Gerson Domingues. E-mail: gersondomingues62@gmail.com 


\section{Mechanisms that favor gastroesophageal reflux a. Transient lower esophageal sphincter relaxations}

The main pathophysiological mechanism of GERD is the transient relaxation of the LES (TLESR) ${ }^{(11,12)}$. The TLESR is mediated by the vagus nerve and strongly influenced by the proximal gastric distension, food, or gas, which precipitate the activation of mechanoceptors adjacent to the cardia. Patients with GERD do not present a higher number of TLESR episodes than control individuals; however, in patients with GERD, TLESRs are more associated with acid reflux ${ }^{(12)}$.

Acid reflux is much more common than non-acid reflux in the etiopathogenesis of GERD: in less than $10 \%$ of the patients, the reflux may be weakly acid or even alkaline ${ }^{(13)}$.

The so-called "gastric reflux" contains harmful material that is capable of injuring the esophagus and/or generating symptoms. Esophageal exposure to gastric reflux is therefore the primary determinant of disease severity. The greater or lesser intensity of esophagitis is related to the time of acid exposure, $\mathrm{pH}$ of the refluxed gastric content, and resistance of the esophageal mucosa ${ }^{(13)}$.

\section{b. Hiatal hernia}

Hiatal hernia $(\mathrm{HH})$ is defined by the proximal migration of the LES in relation to the DC, which occurs mainly by the weakening or rupture of the phrenoesophageal ligament and results in a more incompetent anti-reflux barrier ${ }^{(14)}$. The Brazilian Consensus on GERD based on Evidence quotes $\mathrm{HH}$ as a risk factor for the persistence of symptoms to clinical treatment ${ }^{(15)}$. HH with a size larger than $3 \mathrm{~cm}$ or more is related to significantly higher levels of acid exposure in the distal esophagus and erosive esophagitis ${ }^{(14)}$. Patients with $\mathrm{HH}$ have more reflux episodes and higher acid exposure than normal patients ${ }^{(15)}$. Moreover, the gastric content that is retained in the hernial sac (between the LES and the diaphragmatic crura) refluxes when the LES relaxes during swallowing, characterizing the phenomenon of superimposed reflux ${ }^{(16,17)}$.

\section{c. Acid pocket}

After meals, it was observed that the content that refluxes into the esophagus has comparatively more acid than the gastric body and stems from a region near the EGJ where an acid "pouch" is found, resulting from the neoformation of acidic supernatant from the parietal cells in the proximal gastric region ${ }^{(18,19)}$. The acid pouch volume is larger in patients with GERD than in controls, and larger acid pouches are found in patients with GERD and large $\mathrm{HH}(>3 \mathrm{~cm})^{(20)}$. It has been shown that the location of the acid pouch is more important than the volume: supradiaphragmatic pouches result in $74 \%$ to $85 \%$ of acid reflux during TLESR, while more distal pouches result in $7 \%$ to $20 \%$ of acid reflux during TLESR ${ }^{(18)}$.

\section{d. Esophageal clearance}

After the reflux reaches the esophagus, the main defense against the refluxed acid content is the mechanical esophageal clearance, done by peristalsis and the chemical clearance, promoted by the alkaline $\mathrm{pH}$ of saliva ${ }^{(15,21)}$

\section{e. Slow gastric emptying}

The rationale for slow gastric emptying rely on the hypothesis that this phenomenon generates gastric distension, which could trigger TLESR episodes ${ }^{(22)}$.

\section{f. Gastroesophageal valve}

Patients with GERD have more obtuse insertion angles than controls, resulting in a higher degree of opening of the EGJ and a higher number of reflux events ${ }^{(15,17)}$.

\section{g. Impairment of reflux clearance}

Under normal conditions, the primary peristalsis induced by swallowing brings down the esophageal bicarbonate-rich saliva, promoting chemical clearance and $\mathrm{pH}$ normalization. However, it is important to mention that the chemical clearing of reflux is impaired by the reduced amplitude of peristaltic muscle contraction, as observed in patients with erosive esophagitis compared to normal controls ${ }^{(23)}$. Moreover, volumetric clearing in the distal esophagus is aided by the action of secondary peristalsis, which is a reflex and is mediated by the stimulation of mechanical receptors that respond to distension of the distal esophageal walls caused by reflux ${ }^{(24)}$.

\section{Factors that influence symptom perception}

There may be a low correlation between the presence of acid reflux and symptoms. This is sometimes observed in patients with more severe GERD symptoms who may have low esophageal acid exposure, while those with mild symptoms often have a high acid exposure in the distal esophagus. This observation suggests that there are other factors besides the acid reflux that influence the perception of symptoms, such as the sensitivity of each individual in the perception of stimuli, which is related to the psycho-emotional aspect. Stress, tension, anxiety, and depression may be factors that influence sensitivity, i.e., the generation of symptoms ${ }^{(18)}$ (visceral hypersensitivity).

\section{a. Characteristics of reflux}

With the implementation of impedance-pHmetry, it was possible to characterize the reflux as to its acidity and composition, as well as to identify the level of its rise, allowing the study of the relationship between these variables and GERD symptoms. The reflux may be classified as acid $(\mathrm{pH}<4)$ and non-acid, which is subdivided into mildly acid ( $\mathrm{pH} 4-7)$ and mildly alkaline $(\mathrm{pH}>7)$.

Reflux episodes with $\mathrm{pH}<4$ are capable of generating symptoms, but impedance-pHmetry studies suggest that a certain percentage of patients with symptomatic episodes are associated with non-acid reflux ${ }^{(25)}$. In this context, a recent meta-analysis drew attention to the importance of non-acidic reflux episodes, although in low incidence, as a cause of symptoms, especially in patients who are non-responsive to proton pump inhibitors (PPIs) ${ }^{(25)}$.

Reflux may contain other harmful constituents besides gastric hydrochloric acid, such as pepsin, trypsin, or bile acids. Studies have shown that biliary reflux and mixed (acid-biliary) reflux account for only $6-9 \%$ and $12 \%$ of symptomatic reflux, respectively, in patients not using PPIs ${ }^{(26,27)}$.

\section{b. Contraction of the longitudinal muscle of the esophagus}

The presence of acid in the esophagus may also produce symptoms by inducing the spasm of the longitudinal muscles of the esophagus, which is one of the causes of heartburn. This finding suggests that a motor disorder may be the cause of heartburn, associated or not with acid reflux ${ }^{(28)}$. 


\section{c. Integrity of the esophageal mucosa}

In patients with erosive esophagitis, a clear breakdown of the squamous epithelium barrier is observed, which allows the reflux components to stimulate nociceptors in the lamina propria, causing symptoms. In patients with non-erosive GERD, it has been suggested that a microscopic damage to the mucosa may be a factor associated with the development of symptoms ${ }^{(29)}$. A microscopic change in the mucosa to be considered is the presence of dilated intercellular spaces (DIS), which increase the esophageal mucosa permeability. It is worth mentioning, however, that the relationship between the presence of these changes and symptom perception has not been proven ${ }^{(30)}$.

\section{d. Hypersensitivity}

The perception of symptoms in GERD is related) to the increased sensitivity of the esophagus to several stimuli. This visceral hypersensitivity could be a consequence of the positive regulation of peripheral afferent nerve receptors by the acid-induced inflammation ${ }^{(31)}$.

In addition to peripheral sensitization, sensitization of a central nature plays an essential role in esophageal hypersensitivity. The hypothesis is that acid stimulation in the esophagus promotes sensitization of the cingulate and insular cortex, which are part of the limbic system and process and modulate the sensory signals of the gastrointestinal tract. Consequently, there is a reduction in the pain threshold, which starts to occur with non-painful stimuli ${ }^{(32,33)}$.

\section{DIAGNOSIS}

\section{Clinical presentation}

The typical symptoms of GERD are heartburn and regurgitation. atypical manifestations of the disease, which may not be accompanied by any of the typical symptoms, include: chest pain and otorhinolaryngological and pulmonary manifestations such as cough, laryngitis, asthma, hoarseness, hawking, and globus sensation $^{(34)}$. Chronic cough, chronic laryngitis, and asthma are multifactorial processes that may have reflux as a potential aggravating factor and, therefore, GERD may not be the only cause of these manifestations ${ }^{(35)}$.

Studies have shown that GERD may interfere in the quality of sleep, and heartburn may occur during the sleep period in $25 \%$ of the cases ${ }^{(36)}$. Therefore it is important to note that nighttime heartburn and complaints related to sleep quality are more frequent in patients with GERD and that the treatment of these patients with PPIs may improve sleep quality ${ }^{(37)}$.

The diagnosis based only on the anamnesis and physical examination for patients aged less than 45 years, with typical GERD symptoms, without warning signs (anemia, digestive hemorrhage, weight loss, dysphagia, and odynophagia), and without further investigation, is a conduct recommended by many authors, including the Latin American GERD Consensus ${ }^{(38)}$. The III Brazilian Consensus on GERD, however, recommended that every patient with suspected or diagnosed GERD should undergo an upper digestive endoscopy (UDE) before the beginning of treatment ${ }^{(9)}$. This guideline is based on the fact that the UDE is a safe and an easily performed procedure, widely available, and of low cost in our environment, besides excluding eventual diseases that may occur with non-characteristic symptoms.

\section{Non-erosive reflux disease (NERD)}

It is the most frequent form of the disease, defined by the presence of classic or atypical GERD symptoms associated with reflux and the absence of lesions in the endoscopic examination ${ }^{(1)}$. The patients diagnosed with GERD constitute a heterogeneous group, since a portion of these patients present symptoms related to the esophageal exposure to abnormal acid, while others are symptomatic, presenting symptoms associated with reflux, but with a normal total time of acid exposure, which is called esophageal reflux hypersensitivity ${ }^{(39)}$. On the other hand, some patients with reflux symptoms neither present evidence of the presence of abnormal acid reflux nor of the association with reflux. It has been suggested as a differential diagnosis that the latter present symptoms as a consequence of inflammation, gastrointestinal motility abnormalities, or visceral hypersensitivity (functional pyrosis) ${ }^{(39,40)}$.

The diagnosis of laryngo-pharyngeal reflux (LFR) is more difficult than in typical GERD because of the lack of definitive diagnostic methodology, since most diagnostic tests for LFR, such as laryngoscopy, UDE, and esophageal pHmetry, have shown low sensitivity in detecting that reflux may be the cause of laryngeal symptoms. Therefore, there is no diagnostic test that unequivocally characterizes any extra-esophageal symptom to GERD ${ }^{(41)}$.

\section{Erosive reflux disease}

It consists of the classic presentation of the disease with the occurrence of suggestive symptoms and the presence of erosions in the UDE, although the exam does not have a high specificity ${ }^{(42)}$. The most frequently used classification nowadays is the Los Angeles classification $^{(43)}$ (FIGURE 1).

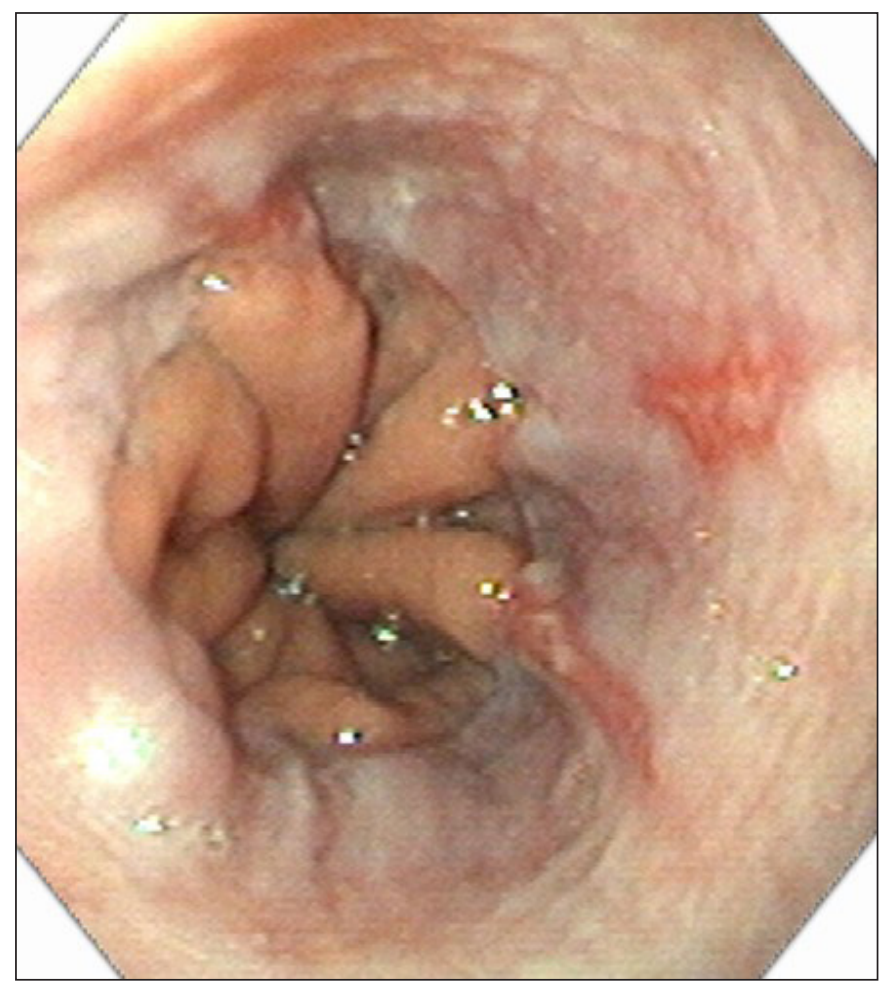

FIGURE 1. Erosive GERD. Presence of mucosal erosions. Esophagitis grade A according to the Los Angeles classification ${ }^{(44)}$. 


\section{PPI testing}

As above mentioned, the empirical therapeutic test with standard-dose PPIs is satisfactory in some cases, allowing the inference of the GERD diagnosis ${ }^{(45)}$. The test has, however, limitations due to its low specificity and because there is no standardization regarding the drug to be used, the dose, or the observation time. Due to these considerations, the Brazilian GERD Consensus does not recommend the use of the therapeutic test ${ }^{(9)}$.

\section{Endoscopic examination and esophageal biopsy}

The endoscopic examination is indicated for cases in which it might contribute to the diagnosis of lesions caused by the reflux, such as in the characterization of erosions and enabling the performance of biopsies, which are indispensable for the diagnosis of complications such as Barrett's esophagus, esophageal ulcers, stenosis, and esophageal adenocarcinoma ${ }^{(46,47)}$.

\section{24-hour pHmetry or prolonged ambulatory pHmetry}

The test evaluates the acidic $\mathrm{pH}$ inside the esophagus. It is particularly indicated for patients with the non-erosive form of the disease, for the evaluation of patients refractory to PPIs, and in situations in which the diagnosis of GERD is questionable. It must be remembered that the 24-hour $\mathrm{pH}$ measurement is the only test that allows us to verify the association between reflux and the presence of symptoms ${ }^{(46)}$.

Very satisfactory results in the determination of esophageal acid $\mathrm{pH}$ have been described with the use of Bravo $^{\circledR}$ capsule (Medtronics Inc., USA), which is an improvement of extended pHmetry. The capsule allows the period of assessment of intra-esophageal $\mathrm{pH}$ to be extended from 24 to 48 hours and up to 96 hours, which may represent an increase of approximately $25 \%$ in the diagnostic capacity. Extending the monitoring time may be especially useful for patients with infrequent symptoms and to optimize the refluxsymptom association $^{(48,49)}$.

\section{7. $\mathrm{pH}$-impedance}

It is currently considered the gold standard test for the diagnosis of GERD ${ }^{(50,51)}$. It allows the identification of the food bolus direction, in anterograde (deglutition) or retrograde (reflux), differentiating between the physical (liquid, gaseous or mixed) and chemical properties of the food bolus, characterizing the reflux episodes in acid and non-acid. The 24-hour monitoring by the impedance-pHmetry system has greater sensitivity than pHmetry alone in the detection of gastroesophageal reflux ${ }^{(40)}$ (FIGURE 2). The indications are the same as those of 24-hour pHmetry.

$\mathrm{pH}$-impedance can be performed with or without PPI therapy. Basically, when the diagnosis of GERD has not yet been established, the study should be better performed without the use of PPIs. On the other hand, the study with the use of PPIs is reserved for patients whose GERD diagnosis has already been established, but there is the persistence of symptoms, or in the evaluation of the treatment in patients with Barrett's esophagus ${ }^{(48)}$.

Recently, it has been sugggested a role to non-acid (or weakly acidic) reflux in the genesis of otorhinolaryngological symptoms, especially cough, hoarseness and globus, in patients being treated with PPIs ${ }^{(25)}$. In these patients with LFR, especially those in whom there was no response to the test with PPIs or the response was partial, $\mathrm{pH}$-impedance may reveal the association of symptoms with acid and non-acid reflux ${ }^{(48)}$. New parameters in esophageal $\mathrm{pH}$-impedance analysis were recently introduced: the post-reflux swallow-induced peristaltic wave (PSPW) index and mean nocturnal basal impedance $(\mathrm{MNBI})^{(52,53)}$. With the use of these new parameters, it was possible to increase the spectrum of GERD diagnosis in patients whose association between reflux and symptoms was not evident during the test $\mathrm{t}^{(52,53)}$.

PSPW evaluates the effectiveness of esophageal chemical clearance, referring to a swallow that occurs within 30 seconds of a reflux event. The PSPW index is defined as the number of events followed by a PSPW divided by the total number of reflux events, being very useful in the distinction between GERD and functional heartburn. This parameter is an independent predictor of refractoriness to IBP ${ }^{(54)}$. The percentage value of PSPW is lower in patients with abnormal acid exposure compared to healthy volunteers and patients with functional heartburn ${ }^{(52)}$.

The nocturnal basal impedance of the esophageal mucosa MNBI is a measure of permeability and, therefore, translates the integrity of the esophageal mucosa in the distal esophagus. This parameter is measured during sleep, where we observe a lower number of swallows that can impact the result of the evaluation. MNBI increases the diagnostic range of pHmetry because, like PSPW, it helps in the differential diagnosis between NERD and functional heartburn ${ }^{(54)}$. A prospective study showed that MNBI has a predictive value for symptomatic response to anti- reflux therapies ${ }^{(55)}$. Patients with abnormal acid exposure time have lower baseline impedance values in the distal esophagus compared to healthy controls and patients with functional heartburn ${ }^{(45)}$.

\section{Lyon Consensus}

According to the Lyon Consensus ${ }^{(50)}$, the main modifications proposed for the diagnosis of GERD are as follows:

In the endoscopic examination, confirmatory evidence for GERD must be considered: esophagitis grades C and D (Los Angeles classification) and peptic stenosis. Esophagitis grades A and B may be nonspecific, provided that they may occasionally be present in normals. Barrett's epithelium must be confirmed by biopsy.

On $\mathrm{pH}$-impedance, esophageal acid exposure time $<4 \%$ is normal (physiologic) and $>6 \%$ abnormal. Intermediate values: inconclusive.

Reflux monitoring (pHmetry/impedance-pHmetry) should be performed without the use of PPIs.

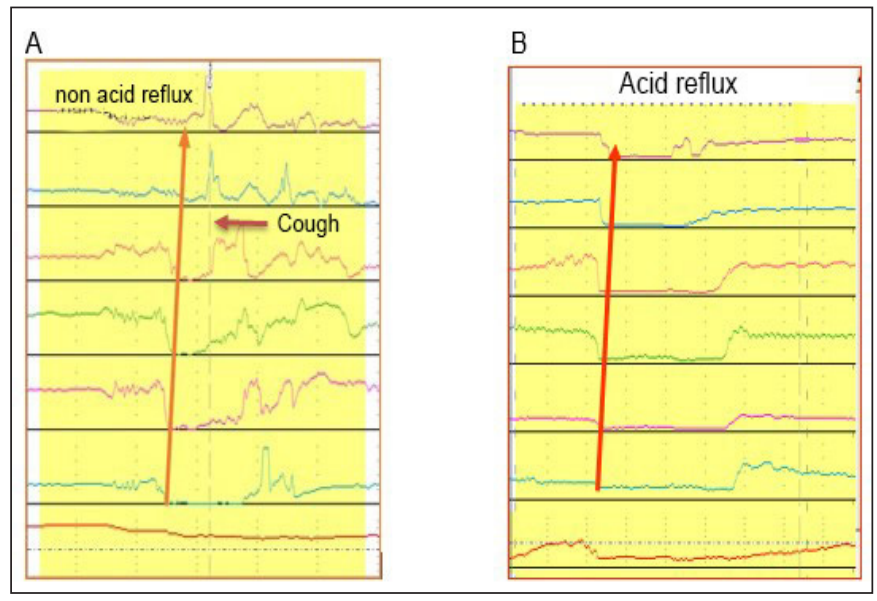

FIGURE 2. $\mathrm{pH}$-impedance tracing demonstrating the presence of: A. An episode of non-acid reflux (slightly acidic) associated with a cough episode. B. An episode of acid reflux. 


\section{TREATMENT}

The clinical therapy aims to minimize the harmful effects to the esophagus of the refluent material (reflux), whose $\mathrm{pH}$ in the absolute majority of times is acidic. It aims, therefore, to relieve symptoms, heal lesions when present, avoid recurrences, and prevent complications. Behavioral, pharmacological, endoscopic, and surgical therapeutic modalities are available for the treatment of GERD. The endoscopic treatment, although quite promising, is still not consensually indicated and therefore, it must not be recommended as an alternative ${ }^{(56)}$.

The ideal therapy should aim at correcting the motor defects of the disease, particularly the TLESR. With this objective, products such as Baclofen, a type B agonist of the gamma-aminobutyric acid (GABA) receptor, showed some satisfactory therapeutic results; however, it presents side effects that limit its use ${ }^{(57)}$.

\section{Clinical treatment}

The great majority of patients benefit from clinical treatment that should encompass behavioral and pharmacological measures.

Apparently, patients with erosive GERD may respond better to treatment than those with the non-erosive form ${ }^{(58)}$. However, it is worth highlighting that a well conducted meta-analysis showed that, when the diagnosis is accurately established with the inclusion of functional tests, patients with the non-erosive form respond in a similar manner as those with the erosive form ${ }^{(59)}$.

\section{a. Behavioral measures}

Change in lifestyle is part of the GERD treatment, comprising the so-called behavioral measures, which aim to avoid situations that promote or facilitate gastroesophageal reflux (FIGURE 3).

The reduction in body weight is important. There is evidence of a significant association between symptomatology improvement and body mass index (BMI) reduction in obese patients who have lost at least $2 \mathrm{~kg} / \mathrm{m}^{2}$ in $\mathrm{BMI}{ }^{(60)}$. So, the reduction in body weight is important.

\begin{tabular}{|c|c|}
\hline Behavioral measure & Note \\
\hline $\begin{array}{c}\text { Elevation of the head of the } \\
\text { bed }(15 \mathrm{~cm}) \text {. Preference for } \\
\text { right lateral decubitus. }\end{array}$ & $\begin{array}{c}\text { Indicated in more severe } \\
\text { cases, especially when } \\
\text { there is nocturnal reflux. }\end{array}$ \\
\hline $\begin{array}{c}\text { Avoid lying down after } \\
\text { meals: wait for 2-3 hours. }\end{array}$ & $\begin{array}{c}\text { Important measure } \\
\text { particularly in nocturnal } \\
\text { reflux. }\end{array}$ \\
\hline $\begin{array}{c}\text { Body weight reduction } \\
\text { in obese people and } \\
\text { overweight patients. }\end{array}$ & $\begin{array}{c}\text { Elevated intragastric } \\
\text { pressure and fatty infiltration } \\
\text { of the esophagogastric } \\
\text { junction in these cases } \\
\text { are factors that favor } \\
\text { gastroesophageal reflux. }\end{array}$ \\
\hline $\begin{array}{c}\text { Avoid: fatty foods, alcohol, } \\
\text { chocolate, tomatoes, coffee, } \\
\text { tea, carbonated drinks. }\end{array}$ & $\begin{array}{c}\text { Selective elimination, } \\
\text { particularly when there is a } \\
\text { food/symptom correlation. }\end{array}$ \\
\hline
\end{tabular}

FIGURE 3. Behavioral measures in the treatment of GERD ${ }^{(17,69)}$.
No consistent associations in the relationship between GERD and certain diets have been demonstrated, with varying levels of evidence and degrees of recommendation. However, from a practical point of view, instructions regarding the diet such as eating slowly, avoiding liquids at meals, and avoiding foods that notoriously trigger symptoms (such as fatty foods, chocolate, tomatoes, etc.) may be recommended according to the clinical conditions and the patient's acceptance, with satisfactory results.

\section{b. Pharmacological treatment}

Pharmacologic options are: I) proton pump inhibitors, II) antacids, III) histamine $\mathrm{H} 2$ receptor blockers, IV) alginate.

\section{Proton pump inhibitors (PPIs)}

In clinical practice, the treatment of choice are the PPIs, which have high healing rates and are safe and effective drugs. PPIs inhibit acid secretion by inactivating the hydrogen-ATPase molecules (proton pump) of parietal cells (TABLE 1).

TABLE 1. Proton pump inhibitors. Daily doses.

\begin{tabular}{lc}
\hline Proton pump inhibitor & Daily standard dose/mg \\
\hline Omeprazole & 40 \\
Lansoprazole & 30 \\
Pantoprazole/pantoprazole & 40 \\
Rabeprazole & 20 \\
Esomeprazole & 40 \\
Dexlansoprazole & $30-60$ \\
\hline
\end{tabular}

PPIs have been widely used for decades, but the number of recent publications questioning their safety has increased dramatically, causing considerable patient anxiety. Evidence has shown that they are risk-free drugs with relatively rare adverse effects and very low mortality ${ }^{(61,62)}$. There are certainly cases where there is a risk of vascular complications, regardless of the use of PPIs, such as in elderly patients with diabetes, hypertension, and history of strokes, who often require aspirin for prophylaxis of cardio-cerebrovascular events ${ }^{(63)}$.

International guidelines have indicated that young patients with typical symptoms should first undergo a therapeutic trial with PPIs ${ }^{(64)}$. The test consists of administering a full dose of PPI for 4 to 8 weeks and observing whether the clinical outcome is satisfactory. However, some restrictions should be remembered because there is no standardization regarding which PPI to use, the dose, and effective observation time, in addition to limitations regarding the diagnostic establishment for this type of conduct: $78 \%$ sensitivity and $54 \%$ specificity ${ }^{(65)}$. On the other hand, in young patients with typical complaints and without other comorbidities, the therapeutic test may be the initial option.

PPIs should be prescribed for eight-week treatment periods (although healing can often occur in four weeks) for symptomatic relief and healing of the erosive form of the disease. In general, there are no major differences between the various PPIs, but in certain cases, they may determine different clinical responses. Hence the recommendation that: if the response with one PPI is unsatisfactory, it should be replaced by another ${ }^{(12)}$.

Pharmacological treatment with PPIs should be started with the standard dose once a day, approximately $30-40$ minutes before breakfast, except for dexlansoprazole, which can be taken regardless of food and has a longer plasma concentration time ${ }^{(66,67)}$. 
There are no major differences between the use of one daily morning dose or two half-doses (morning and before dinner) and, therefore, when there is a predominance of nocturnal symptoms, the PPI (half dose) can be prescribed twice a day ${ }^{(9)}$. In cases in which there is a partial response to treatment, the double dose of the product should be considered, and eventually the change to another PPI ${ }^{(68)}$.

In patients under treatment with PPIs, the recovery of nocturnal gastric acid secretion characterizes nocturnal acid escape, which leads to the occurrence of symptoms during the night. Acid leak is frequently observed with the most currently used PPIs, whose pharmacokinetic characteristic involve the release of the drug at a single time point when used in a single daily dose in the morning. Although increasing the PPI dose to two daily doses is a common medical procedure, patients may eventually continue to experience symptoms related to nocturnal acid leak ${ }^{(69)}$.

It is important to mention that in up to $40 \%$ of patients, the result might not be totally satisfactory due to the perpetuation of symptoms or only partial resolution of symptoms ${ }^{(5)}$. In these cases, it is relevant to carefully observe patient compliance with the medical prescription, since the level of patient adherence to treatment may be low, impairing the therapeutic outcome $\mathrm{e}^{(70,71)}$.

Other less potent agents can be used in cases where symptoms are mild or intermittent or as supplemental therapy to PPIs ${ }^{(9)}$. These are:

\section{Alkalines (or antacids)}

Alkalines (or antacids) are used to neutralize gastric acid secretion, but they have a low neutralization capacity and short duration, which leads to low compliance by patients, serving for immediate relief of symptoms.

\section{III. $\mathrm{H}_{2}$ histamine receptor blockers}

$\mathrm{H}_{2}$ histamine receptor blockers (cimetidine, nizatidine, ranitidine, and famotidine). They were very important as the first inhibitors of acid secretion since the launch of cimetidine in the late 1970 s. Currently, they correspond to the second line of PPIs. They can eventually be used in the control of nocturnal acid secretion, although the tachyphylaxis that they present after a few days of use is a restrictive factor that must be considered ${ }^{(72)}$.

\section{Alginate}

Extracted from seaweed, it forms a real barrier on the esophageal mucosa and is associated with sodium bicarbonate and calcium carbonate ${ }^{(73)}$. The formulation containing alginate, sodium bicarbonate and calcium carbonate relief of symptoms irrespective of the nature of the stimulus (acid, pepsin, bile). They can be administered in association with PPIs, achieving satisfactory therapeutic results ${ }^{(73,74)}$.

\section{c. Maintenance treatment}

GERD is a chronic condition, and the improvement of symptoms observed with the acid suppression, promoted by the full (or possibly doubled) dose of PPIs, may be followed by the return of symptoms when treatment is discontinued, since the pathophysiological defect persists. The return of clinical manifestations may occur particularly in cases of more intense reflux, and in this sense, up to $80 \%$ of patients with erosive esophagitis, within 12 months of treatment discontinuation, and after the satisfactory response of the first phase of treatment, have a major or minor relapse of symptoms ${ }^{(15,75)}$.

Thus, at the end of the acute phase of treatment, certain patients require maintenance care: PPIs can be prescribed in half-daily doses or on-demand (administration when the patient presents symptoms $)^{(76)}$. Interestingly, approximately $20 \%$ of patients remain asymptomatic with the use of antacids, or alginate and behavioral measures after standard IBP treatment ${ }^{(17)}$.

The risk of adverse events from long-term PPI use is relatively modest ${ }^{(77)}$, although publications (some of which have been criticized for inadequacies) have reported that these can occur with prolonged PPI use. A well-conducted randomized controlled trial showed no association between adverse events and the use of PPIs administered for three years, with the possible exception of an increased risk of enteric infections ${ }^{(78)}$. In summary, frail elderly patients on chemotherapy should be more carefully monitored, particularly regarding the dosages of calcium, vitamin B12, and magnesium as well as enteric infections.

\section{Surgical treatment}

Surgical treatment (fundoplication) is indicated in the presence of complications such as stenosis, ulcerations, and hiatal hernias larger than $3 \mathrm{~cm}$, being an option for long-term therapy, or for cases where symptoms are refractory to clinical treatment. In general, however, surgical intervention is not recommended for patients who do not respond satisfactorily to clinical treatment ${ }^{(79)}$.

There is an equivalence between clinical treatment with IBP $(93 \%)$ and surgical Nissen fundoplication treatment $(90 \%)$ among patients who have been in remission for three years ${ }^{(79)}$. Long-term surgical follow-up studies are not yet available, in which case patients should be informed that over time, reintroduction of clinical treatment or reoperation is often necessary ${ }^{(79)}$.

\section{New therapies}

Despite the therapeutic success of PPIs in the pharmacological treatment of GERD, there are still areas with unmet needs such as: severe erosive esophagitis (grades $\mathrm{C}$ and $\mathrm{D}$ ), with possible therapeutic failure in $20-40 \%$, and non-erosive reflux disease, which may have up to $40 \%$ of unsatisfactory therapeutic response. In this context, new options of clinical, endoscopic, and surgical therapeutic modalities have been developed, some still in the research area ${ }^{(5)}$.

\section{a. Pharmacological treatment}

\section{PCABs (potassium competitive acid blockers)}

An innovative approach was the development of PCABs, which are reversible proton pump blockers ( $\mathrm{H}+/ \mathrm{K}+$-ATPase) that block the $\mathrm{K}+$ exchange channel, resulting in rapid, competitive, and reversible inhibition of gastric acid secretion. Among the PCABs in clinical use in Brazil, Japan and South Korea, Vonoprazan stands out with important clinical data available ${ }^{(80)}$. Considering the limitations of the currently available anti-secretory compounds, particularly PPIs, this new class of drugs achieves faster, more potent, and prolonged acid suppression, with the possibility of solving many of the clinical needs not achieved by PPIs ${ }^{(81)}$.

\section{Mucous membrane protector}

Rebamipide is an amino derivative of quinolinone that serves as a mucosal protector by increasing the production of prostaglandin EP4 and epidermal growth factor, with antioxidant properties. It is marketed in south-east Asian countries and is indicated for the treatment of acid-related diseases of the oesophagus, including after endoscopic submucosal resection procedures ${ }^{(82)}$. 


\section{Prokinetics}

As mentioned above, there is no indication for the use of prokinetics in the treatment of GERD. Recently, however, preliminary studies have shown that acotiamide and prucalopride ${ }^{(83,84)}$ may play a role in the clinical treatment of GERD. Acotiamide ${ }^{(83,84)}$ is indicated for the treatment of functional dyspepsia and prucalopride in the treatment of chronic constipation, and both drugs have shown beneficial effects on esophageal function such as an increase in the EGJ pressure and in the distal esophageal contraction, with an improvement in primary peristalsis, reduction in the number of reflux episodes, decrease in the acid exposure time, and acceleration of gastric emptying ${ }^{(83,85)}$.

\section{b. Endoscopic therapy}

Minimally invasive endoscopic or endoluminal procedures for GERD treatment have been proposed as alternative therapeutic strategies to medical or surgical treatment. Cases with indication for endoscopic procedures include patients with typical GERD symptoms, presence of erosive esophagitis grades A and B (Los Angeles), normal endoscopic examination and abnormal acid exposure, and $\mathrm{HH}$ of dimensions $<3 \mathrm{~cm}$ with partial response to IBP treatment ${ }^{(86)}$.

Of the various endoscopic techniques proposed for the treatment of GERD, we highlight:

(I) Stretta ${ }^{\circledR}$ procedure with radiofrequency. The system applies radiofrequency energy to the LES and cardia. The motor response responsible for the effect depends on the increased thickness of the EGJ consequent to the modulation of local muscles and the decrease in the frequency of transient relaxations of the LES. Meta-analysis involving 28 studies and 2,468 patients indicated that the Stretta procedure significantly improved GERD-related symptoms and decreased the percentage of patients using PPIs ${ }^{(86)}$. Future long-term follow-up studies are needed.

(II) TIF procedure (transoral incisionless fundoplication). It is an endoscopic technique performed with Esophy $\mathrm{X}^{\circledR}$ to create an anterior fundoplication. The procedure is performed under general anesthesia and a 3 to $5 \mathrm{~cm}$ long valve with a circumference of 200 to 300 degrees is constructed to prevent gastroesophageal reflux. Studies have characterized the efficacy and safety of the procedure, showing improvement of symptoms, quality of life, and reduction of acid exposure time and the use of PPIs ${ }^{(87)}$. The durability of the effectiveness of the procedure is a point to be better defined ${ }^{(88)}$ : follow-up studies are needed.

\section{c. Surgical therapy}

Laparoscopic fundoplication is the traditional recommendation for patients who do not wish to use PPIs chronically and eventually do not respond to the doubled dose of daily PPIs. It has an initial success rate of over $90 \%$ in centers with good esophageal surgical training ${ }^{(89)}$. It is worth mentioning, however, that fundoplication is technically difficult to perform and is associated with some adverse effects during the post-procedure, such as the patient's inability to eructate or vomit, and distension sensation present in up to $25 \%$ of patients (gas bloat syndrome) ${ }^{(89)}$. Recurrence is also relatively high with a 10-year average of $10-15 \%{ }^{(90)}$.

Recently, LINX ${ }^{\circledR}$ (magnetic sphincter augmentation) was introduced as a surgical alternative for GERD treatment aiming at reducing adverse events observed in the traditional laparoscopic fundoplication $^{(91)}$. The device consists of interconnected magnets wrapped in a titanium cover forming a ring like a bracelet, positioned circumferentially around the esophagus near the JEG ${ }^{(92)}$. The procedure is safe and minimally invasive with good results in many centers, with contraindication for patients with allergy to titanium and nickel ${ }^{(93)}$. Future studies should determine the long-term efficacy.

\section{Authors' contribution}

Domingues G and Moraes-Fiho JPP collected and analyzed data, drafted, critically revised de manuscript and approved the final manuscript draft.

\section{Orcid}

Gerson Domingues: 0000-0003-0431-451X.

Joaquim Prado P de Moraes-Filho: 0000-0003-1280-6047.

Domingues G, Moraes-Filho JPP. Doença do refluxo gastroesofágico: uma abordagem prática. Arq Gastroenterol. $2021 ; 58(4): 525-33$.

RESUMO - A doença do refluxo gastroesofágico (DRGE) apresenta manifestações típicas, pirose e/ou regurgitação, assim como, manifestações atípicas, pigarro, laringite, rouquidão, tosse crônica, asma, alterações do sono. Existem dois fenótipos da doença: a DRGE erosiva, quando são identificadas erosões pela endoscopia digestiva alta (EDA) e a DRGE não-erosiva, com mucosa esofágica de aspecto endoscópico normal. Ao exame físico não costumam ser encontrados achados relevantes, mas a obesidade deve ser destacada como importante fator agravante do refluxo. O tratamento é estabelecido com base nos achados clínicos e, conforme a situação clínica, em exames complementares como a EDA. Nos casos duvidosos onde o diagnóstico preciso se impõe, o exame indicado é a pHmetria esofágica ou a impedância-pHmetria. O tratamento clínico é dividido em medidas comportamentais/dietéticas e medidas farmacológicas. A maioria dos pacientes se beneficia com o tratamento clínico, mas o tratamento cirúrgico pode estar indicado como na presença de hérnia hiatal de maior dimensão e nas complicações da doença.

Palavras-chave - Doença do refluxo gastroesofágico; diagnóstico; tratamento. 


\section{REFERENCES}

1. Vakil N, Zanten SV, Kahrilas P, Dent J, Jones R, Global Consensus Group. The Montreal Definition and Classification of Gastroesophageal Reflux Disease: a Global Evidence-Based Consensus. Am J Gastroenterol. 2006;101:1900-20.

2. Moraes-Filho JPP, Chinzon D, Eisig E, Hashimoto CL, Zaterka S. Prevalence of heartburn and Gastroesophageal Reflux Disease in the urban Brazilian population. Arq Gastroenterol. 2005;42:122-7.

3. Fass R. Effect of Gastroesophageal Reflux Disease on sleep. J Gastroenterol Hepatol. 2009;25 (Suppl. 1):S41-S44

4. Bytzer P, Jones R, Vakil N, Junghard O, Lind T, Wernersson B, et al. Limited ability of the proton-pump inhibitor test to identify patients with gastroesophageal reflux disease. Clin Gastroenterol Hepatol. 2012;10:1360-6.

5. Domingues G, Moraes-Filho JPP, Fass R. Refractory Heartburn: A Challenging Problem in Clinical Practice. Dig Dis Sci. 2018:63:577-82.

6. Yadaplati R, Pandolfino JE. Personalized approach in the work-up and management of gastroesophageal reflux disease. Gastrointest Endoscopy Clin N Am. 2020;30:227-38

7. Mittal RK, Balaban DH, Epstein FH. The esophagogastric junction. N Engl J Med. 1997;336:924-32.

8. Mendes-Filho AM, Moraes-Filho JPP, Nasi A, Eisig JN, Rodrigues TN, Barbutti $\mathrm{RC}$, et al. Influence of exercise testing in Gastroeesophageal Reflux in patients with Gastroesophageal Reflux Disease. Arq Bras Cir Dig. 2014;27:3-8.

9. Moraes-Filho JPP, Navarro-Rodriguez T, Barbuti R, Eisig J, Chinzon D, Bernardo $\mathrm{W}$, et al. Guidelines for the diagnosis and management of Gastroesophageal Reflux Disease: an evidence-based consensus. Arq Gastroenterol. 2010;47:99-115.

10. Katz PO, Gerson LB, Vela MF. Guidelines for the diagnosis and management of Gastroesophageal Reflux Disease. Am J Gastroenterol. 2013;108:308-28.

11. Roman S, Holloway R, Keller J, Herbella F, Zerbib F, Xiao Y, et al. Validation of criteria for the definition of transient lower esophageal sphincter relaxation using high-resolution manometry. Neurogastroenterol Motil. 2017;29(2). doi. $10.1111 /$ nmo. 12920

12. Moraes-Filho JPP. Doença do Refluxo Gastroesofágico. Rev Bras Med. 2007;64:1-8

13. Tack J, Pandolfino JE. Phathophysiology of Gastroesophageal Reflux Disease Gastroenterology. 2018;154:277-288.

14. Pandolfino JE, Shi G, Trueworthy B, Kahrilas PJ. Esophagogastric junction opening during relaxation distinguishes nonhernia reflux patients, hernia patients, and normal. Gastroenterology. 2003;125:1018-24.

15. Zachariah RA, Goo T, Lee RH. Mechanism and pathophysiology of Gastroesophageal Reflux Disease. Gastrointest Endoscopy Clin N Am. 2020;30:209-26

16. van Herwaarden MA, Samsom M, Smout AJ. The role of hiatus hernia in gastro-oesophageal reflux disease. Eur J Gastroenterol Hepatol. 2004;16:831-5.

17. Bredenoord AJ, Pandolfino JE, Smout AJ. Gastro-oesophageal reflux disease. Lancet. 2013;381:1933-42.

18. Beaumont H, Bennink RJ, de Jong J, Boeckxstaens GE. The position of the acid pocket as a major risk factor for acidic reflux in healthy subjects and patients with GORD. Gut. 2010;59:441-51.

19. Pandolfino JE, Zhang Q, Ghosh SK, Post J, Kwiatek M, Kahrilas PJ. Acidity surrounding the squamocolumnar junction in GERD patients: "acid pocket" versus "acid film". Am J Gastroenterol. 2007;102:2633-41.

20. Clarke AT, Wirz AA, Manning JJ, Ballantyne SA, Alcorn DJ, McColl KEL. Severe reflux disease is associated with an enlarged unbuffered proximal gastric acid pocket. Gut. 2008;57:292-7.

21. Mittal RK, Lange RC, McCallum RW. Identification and mechanism of delayed esophageal acid clearance in subjects with hiatus hernia. Gastroenterology. 1987;92:130-5.

22. Gourcerol, G. Influence of gastric emptying on gastro-esophageal reflux: a combined pH-impedance study. Neurogastroenterol Motil. 2013:25:800-7.

23. Frazzoni M, Manta R, Mirante VG, Conigliaro R, Frazzoni L, Melotti G. Esophageal chemical clearance is impaired in gastro-esophageal reflux disease-a 24impedance-pH monitoring assessment. Neurogastroenterol Motil. 2013;25:399-406.

24. Savarino E, Gemignani L, Pohl D, Zentilin P, Dulbecco P, Assandri L, et al Oesophageal motility and bolus transit abnormalities increase in parallel with the severity of gastro-oesophageal reflux disease. Aliment Pharmacol Ther. 2011;34:476-86

25. Boeckxstaens GE, Smout A. Systematic review: role of acid, weakly acidic and weakly alkaline reflux in gastro-oesophageal reflux disease. Aliment Pharmacol Ther. 2010;32:334-43.

26. Koek GH, Tack J, Sifrim D, Lerut T, Janssens J. The role of acid and duodenal gastroesophageal reflux in symptomatic GERD. Am J Gastroenterol. 2001;96:2033-40.

27. Marshall RE, Anggiansah A, Owen WA, Owen WJ. The relationship between acid and bile reflux and symptoms in gastro-oesophageal reflux disease. Gut. 1997;40:182-7.
28. Pehlivanov N, Liu J, Mittal RK. Sustained esophageal contraction: a motor correlate of heartburn symptom. Am J Physiol Gastrointest Liver Physiol. 2001;281:G743-51

29. Tobey NA, Gambling TM, Vanegas XC, Carson JL, Orlando RC. Physicochemica basis for dilated intercellular spaces in non-erosive aciddamaged rabbit esophageal epithelium. Dis Esophagus. 2008;21:757-64.

30. Calabrese C, Bortolotti M, Fabbri A, Areni A, Cenacchi G, Scialpi C, et al. Reversibility of GERD ultrastructural alterations and relief of symptoms after omeprazole treatment. Am J Gastroenterol. 2005;100:537-42.

31. Bhat YM, Bielefeldt K. Capsaicin receptor (TRPV1) and non-erosive reflux disease. Eur J Gastroenterol Hepatol. 2006;18:263-70

32. Ma J, Altomare A, Rieder F, Behar J, Biancani P, Harnett KM. ATP: a mediato for HCl-induced TRPV1 activation in esophageal mucosa. Am J Physiol Gastrointest Liver Physiol. 2011;301:G1075-82.

33. Lawal A, Kern M, Sanjeevi A, Antonik S, Mepani R, Rittmann T, et al. Neurocognitive processing of esophageal central sensitization in the insula and cingulate gyrus. Am J Physiol Gastrointest Liver Physiol. 2008;294:G787-94.

34. Moraes-Filho, JPP, Ceconnello I, Gama-Rodrigues JJ, Castro LP, Maria Henry MA, Meneghelli UG, et al. Brazilian Consensus on Gastroesophageal Reflux Disease: proposals for assessment, classification and management. Am J Gastroenterol. 2002;97:241-8.

35. Smith JA, Woodcock A. Chronic cough. N Engl J Med. 2016;375:1544-51.

36. Fass R, Quan SF, O'Connor GE, Ervin A, Iber C. Predictors of heartburn during sleep in a large prospective cohort study. Chest. 2005;127:1658-66.

37. Chen CL, Robert JJT, Orr WC. Sleep symptoms and gastroesophageal reflux. J Clin Gastroenterol. 2008:42:13-17.

38. Cohen H, Moraes-Filho JPP, Cafferata ML, Tomasso G, Salis G, González O, et al. A Latin-American Evidence Based Consensus on Gastroesophageal Reflux Disease. Europ J Gastroenterol Hepatol. 2006;18:349-68.

39. Aziz Q, Fass R, Gyawalli CP, Miwa H, Pandolfino JE, Zerbib F. Functiona esophageal disorders. Gastroenterology. 2016:15;S0016-5085(16)00178-5. doi: 10.1053/j.gastro.2016.02.012

40. Roman S, Gyawali CP, Savarino E, Yadlapati R, Zerbib F, Wu J, et al. Ambulatory reflux monitoring for diagnosis of gastro-esophageal reflux disease: update of the Porto consensus and recommendations from an international consensus group. Neurogastroenterol Motil. 2017;29:1-15.

41. Moore JM, Vaezi MF. Extraesophageal manifestations of gastroesophageal reflux disease: real or imagined? Curr Opin Gastroenterol. 2010;26:389-94.

42. Kahrilas PJ, Shaheen NJ, Vaezi MF. American Gastroenterological Association medical position statement on the management of gastroesophageal reflux disease. Gastroenterology. 2008;135:1383-91.

43. Lundell LR, Dent J, Bennett JR, Blum AL, Armstrong D, Galmiche JP, et al. Endoscopic assessment of oesophagitis: clinical and functional correlates and further validation of the Los Angeles classification. Gut. 1999;45 172-180.

44. Yadaplati R, Vaezi MF, Vela MF, Spechler SJ, Shaheen NJ, Richter J, et al. Management options for patients with GERD and persistent symptoms on proton pump inhibitors: recommendations from an expert panel. Am J Gastroenterol. 2018;113:980-6

45. Strand DS, Kim D, Peura DA. 25 years of proton pump inhibitors: a comprehensive review. Gut and Liver. 2017;11:27-37.

46. Weusten BL, Akkermans LM, van Berge-Henegouwen GP, Smout AJ. Symptom perception in gastroesophageal reflux disease is dependent on spatio temporal reflux characteristics. Gastroenterology. 1995;108:1739-44

47. Velanovich V, Hollingsworth J, Suresh P, Ben-Menachem T. Relationship of gastroesophageal reflux disease with adenocarcinoma of the distal esophagus and cardia. Dig Surg. 2002;19:349-53

48. Domingues G, Moraes-Filho JPP, Domingues AGL. Impact of prolonged 48-h wireless capsule esophageal $\mathrm{pH}$ monitoring on diagnosis of gastroesophagea reflux disease and evaluation of the relationship between symptoms and reflux episodes. Arq Gastroenterol. 2011;48:24-9.

49. Penagini R, Sweis R, Mauro A, Domingues G, Vales A, Sifrim D. Inconsistency in the diagnosis of functional heartburn: usefulness of prolonged wireless $\mathrm{pH}$ monitoring in patients with proton pump inhibitor refractory gastroesophageal reflux disease. J Neurogastroenterol Motil. 2015;21:265-72.

50. Gyawali CP, Kahrilas PJ, Savarino E, Zerbib F, Mion F, Smout AJPM, et al Modern diagnosis of GERD: the Lyon consensus. Gut. 2018;67:1351-62.

51. Domingues G. Multichannel intraluminal impedance and $\mathrm{pH}$. Arq Gastroenterol. 2016;53:129-37.

52. Wang AM, Wang G, Huang N, Zheng YY, Yang F, Qiu X, et al. Association between laryngopharyngeal reflux disease and autonomic nerve dysfunction. Eur Arch Otorhinolaryngol. 2019;276:2283-7. 
53. Herregods TV, Bredenoord AJ, Smout AJ. Pathophysiology of gastroesophageal reflux disease: new understanding in a new era. Neurogastroenterol Motil. 2015;27:1202-13.

54. Lipham JC, Taiganides PA, Louie BE, Ganz RA, DeMeester TR. Safety analysis of first 1000 patients treated with magnetic sphincter augmentation for gastroesophageal reflux disease. Dis Esophagus. 2105;28:305-11.

55. Ganz RA, Edmundowicz SA, Taiganides PA, Lipham JC, C Smith D, Vault KR, et al. Long-term outcomes of patients receiving a magnetic sphincter augmentation device for gastroesophageal reflux. Clin Gastroenterol Hepatol. 2016;14:671-7.

56. Hirano I, Pandolfino JE, Boeckxstaens GE. Functional lumen imaging probe for the management of esophageal disorders: expert review from the clinical practice updates committee of the AGA Institute. Clin Gastroenterol Hepatol. 2017; 15:325-34.

57. Scarpignato C, Sloan JA, Wang DH, Hunt RH. Gastrointestinal pharmacology: practical tips for the esophagologist. Ann N Y Acad Sci. 2020;1481:1-18. doi:10.1111/nyas. 14447.

58. Scarpignato C. Poor effectiveness of proton pump inhibitors in non-erosive reflux disease: the truth in the end! Neurogastroenterol Mot. 2012;24:697-704.

59. Weijenborg PW, Cremonini F, Smout AJPM, Bredenoord AJ. PPI therapy is equally effective in well-defined non-erosive reflux disease and in reflux esophagitis: a meta-analysis. Neurogastroenterol Motil. 2012;24:747-e350.

60. Park SK, Lee T, Yang HJ, Park JH, Sohn CI, Ryu S, et al. Weight loss and waist reduction is associated in improvement of gastroesopghageal disease reflux symptoms: alongitudinal study of 15,295 subjects undergoing health checkups. Neurogastroenterol Motil. 2017;29(5). doi: 10.1111/nmo. 1309.

61. Scarpignato C, Hongo M, Wu JCY, Lottup C, Lazarescu A, Stein E, Hunt R. Pharmacologic treatment of GERD: Where are we now, and where are we going? Ann NY Acad Sci. 2020;1482:193-212.

62. Baik SH, Fung K-W, McDonald CJ. The mortality risk of Proton Pump Inhibitor in 1.9 Million US Seniors: an extended Cox survival analysis. Clin Gastroenterol Hepatol. 2021:13;S1542-3565(21)00017-3. doi: https://doi.org/10.1016/j. cgh.2021.01.014.

63. Batchelor R, Kumar R, Gilmartin-Thomas JFM, Hopper I, Kemp W, Liew D. Systematic review with meta-analysis: risk of adverse cardiovascular events with proton pump inhibitors independent of clopidrogel. Aliment Pharmacol Ther. 2018;48:780-96.

64. Young A, Kumar MA, Thota PN. GERD: a practical approach. Cleveland Clin J Med. 2020;87:223-30

65. Numans ME, Lau J, de Wit NJ, Bonis PA. Short-term treatment with proton pump inhibitors as a test for gastroesophageal reflux disease: a meta-analysis of diagnostic test characteristics. Ann Intern Med. 2004;140:518-27.

66. Behm BE, Peura DA. Dexlansoprazole MR for the management of gastroesophageal reflux disease. Expert Rev Gastroenterol Hepatol. 2011;5:439-45.

67. Fass R, Frasier R. The role of dexlansoprazole modified-release in the management of gastroesophageal reflux disease. Therap Adv Gastroenterol. 2017;10:243-51.

68. Katz PO, Gerson LB, Vela MF. Guidelines for the diagnosis and management of gastroesophageal reflux disease. Am J Gastroenterol. 2013;108:308-28.

69. Khan BA, Sodhi JS, Zargar SA, Javid G, Yattoo GN, Shah A, et al. Effect of bed head elevationduring sleep in symptomatic patients of nocturnal gastroesophageal reflux. J Gastroenterol Hepatol. 2012;27:1078-82.

70. Tucker E, Sweis R, Anggiansah A, Wong T, Telakis E, Knowles K, et al. Measurement of esophago-gastric junction cross-sectional area and distensibility by na endolumenal functional lumen imaging probe for the diagnosis of gastro-esophageal reflux disease. Neurogastroenterol Motil. 2013;25:904-10.

71. Dal-Paz K, Moraes-Filho JPP, Navarro-Rodriguez T, Eisig JN, Barbuti R, Quigley EMM. Low levels of adherence with proton pump inhibitor therapy contribute to therapeutic failure in gastroesophageal reflux disease. Esophagus Dis. $2011 ; 107-13$

72. McRorie J, Kirby JA, Miner PB. Histamine2 - receptor antagonists: rapid development of tachyphylaxis with repeated dosing. World J Gastrointest Pharmacol Ther. 2014;5:57-62.
73. Fass R, Chey WD, Zakko SF, Andhivarothai N, Palmer RN, Perez MC, et al. Clinical trial: the effects of the proton pump inhibitor dexlanzoprazole MR on daytime and nighttime heartburn in patients with non-erosive reflux disease. Aliment Pharmacol Ther. 2009;29:1261-72.

74. Leiman DA, Riff BP, Morgan S, et al. Alginate therapy is effective treatment for GERD symptoms: a systematic review and meta-analysis. Esophagus Dis 2017;30:1-9.

75. Brunner G, Athmann C, Schneider A. Long-term, open-label trial: safety and efficacy of continuous maintenance treatment with pantoprazole for up to 15 years in severe acid-peptic disease. Aliment Pharmacol Therap. 2012;36:37-47.

76. Pace F, Tonini M, Pallota S, Molteni P, Porro GB. Systematic review: maintenance of treatment of gastro-oesophageal reflux disease with proton pump inhibitors taken "on demand". Aliment Pharmacol Therap. 2007;26:195-204.

77. Sandhu DS, Fass R. Current trends in the management of gastroesophageal reflux disease. Gut and Liver. 2018;12:7-16.

78. Moayyedi P, Eikelboom JW, Bosch J, Connolly SJ, Dyal L, Shestakovska O, et al. Safety of proton pump inhibitors based on a large, multi-year, randomized trial of patients receiving rivaroxaban or aspirin. Gastroenterology. 2019;157:682-91.

79. Spechler SJ. Refractory gastroesophageal reflux and functional heartburn. Gastrointest Endosc Clin N Am. 2020;30:325-42.

80. Yang X, Li Y, Sun Y, Zhang M, Guo C, Mirza IA, et al. Vonoprazan: a novel and potent alternative in the treatment of acid-related diseases. Dig Dis Sci. 2018;63:302-311

81. Sugano K. Vonoprazan fumarate, a novel potassium-competitive acid blocker, in the management of gastroesophageal reflux disease: safety and clinical evidence to date. Therap Adv Gastroenterol. 2018;11:1756283X17745776.

82. Araki H, Kato T, Onogi F, Ibuka T, Sugiyama A, Nakanishi T, et al. Combination of proton pump inhibitor and rebamipide, a free radical scavenger, promotes artificial ulcer healing after endoscopic submucosal dissection with dissection size $>40 \mathrm{~mm}$. J Clin Biochem Nutr. 2012;51:185-8.

83. Yamashita H, Okada A, Naora K, Hongoh M, Kinoshita Y. Adding acotiamide to gastric acid inhibitors is effective for treating refractory symptoms in patients with non-erosive reflux disease. Dig Dis Sci. 2019;64:823-31

84. Shibli F, Kitayama Y, Fass R. Novel therapies for gastroesophageal reflux disease: beyond proton pump inhibitors. Curr Gastroenterol Rep. 2020;22:16-28.

85. Kessing BF, Smout AJ, Bennink RJ, Kraaijpoel N, Oors JM, Bredenoord AJ, et al. Prucalopride decreases esophageal acid exposure and accelerates gastric emptying in healthy subjects. Neurogastroenterol Motil. 2014;26:1079-86.

86. Fass R, Cahn F, Scotti DJ, Gregory DA. Systematic review and metaanalysis of controlled and prospective cohort efficacy studies of endoscopic radiofrequency for treatment of gastroesophageal reflux disease. Surg Endosc. 2017;31: 4865-82.

87. Huang X, Chen S, Zhao H, Zeng X, Lian J, Tseng Y, et al. Efficacy of transoral incisionless fundoplication (TIF) for the treatment of GERD: a systematic review with meta-analysis. Surg Endosc. 2017;31:1032-44

88. Trad KS, Barnes WE, Prevou ER, Simoni G, Steffen JA, Shughoury AB, et al. The TEMPO trial at 5 years: transoral fundoplication (TIF 2.0) is safe, durable, and cost-effective. Surg Innov. 2018;25:149-57.

89. Castelijns PSS, Ponten JEH, Vd Poll MCG, Bouvy ND, Smulders JF. Quality of life after Nissen fundoplication in patients with gastroesophageal reflux disease: comparison between long- and short-term follow-up. J Minim Access Surg. 2018;14:213-20.

90. Kessing BF, Broeders JA, Vinke N, Schijven MP, Hazebroek EJ, Broeders IA, et al. Gas-related symptoms after antireflux surgery. Surg Endosc. 2013;27:3739-47.

91. Dunn C, Bildzukewicz N, Lipham J. Magnetic sphincter augmentation for gastroesophageal reflux disease. Gastrointest Endoscopy Clin N Am. 2020;30: $325-42$.

92. Ganz RA, Peters JH, Horgan S. Esophageal sphincter device for gastroesophageal reflux disease. N Engl J Med. 2013;368:719-27.

93. Dunn C, Bildzukewicz N, Lipham J. Magnetic sphincter augmentation for gastroesophageal reflux disease. Gastrointest Endoscopy Clin N Am. 2020;30:325-42. 